\title{
Detection of Aminoglycosides Resistance among Strains of Escherichia Coli Isolated From Patients with Urinary Tract Infection
}

\author{
Waseem Sameer Kwami ${ }^{1}$, Ruaa Abdalghafour Dahab ${ }^{1}$, Ayaat Badawi Merghani ${ }^{1}$, Ruaa Hannan Gad- \\ Alseed $^{1}$, Mosab Nouraldein Mohammed Hamad ${ }^{2 *}$ \\ ${ }^{\mathrm{T}}$ Microbiology Department, Faculty of Medical laboratory Science, Shendi University Sudan \\ ${ }^{2}$ Phylum of Medical Parasitology, Medical Laboratory Sciences Department, Faculty of Health Science, Elsheikh \\ Abdallah Elbadri University, Berber, Sudan
}

*Corresponding Author

Mosab Nouraldein Mohammed Hamad

\author{
Article History \\ Received: 09.11 .2020 \\ Accepted: 20.11 .2020 \\ Published: 22.11 .2020
}

\begin{abstract}
Background: Urinary tract infections attack about 150 million people each year globally and nowadays there is a high emergence of antibiotic resistance strains among E. Coli species that cause UTI. The objective of this study was to detect Aminoglycosides resistance among E. Coli strains isolated from patients with urinary tract infection. Method: A total of 70 urine specimens were collected from patient with symptoms of urinary tract infection in sterile urine containers, and then inoculated in CLED media, incubated at 37c for 24 hours. E. Coli species were identified according to their colonial morphology, indirect gram staining reaction, and biochemical tests. Identified species were tested for antimicrobial susceptibility against the following aminoglycosides: Amikacin, Kanamycin, Streptomycin, Gentamicin, and Tobramycin using Kirby-bauer disc diffusion method. Results: The study revealed that 55.7\% of urinary tract infections were caused by E. Coli. The study also showed that $12.8 \%$ of isolated E. Coli species were resistant to Amikacin, $28.2 \%$ to Gentamicin, $43.6 \%$ to Streptomycin, $48.7 \%$ to Kanamycin, and $53.8 \%$ to Tobramycin. Conclusion: The study concluded that the overall resistance of isolated E. coli species to aminoglycosides was $37.4 \%$ the most powerful Aminoglycoside against E. Coli species was Amikacin.
\end{abstract}

Keywords: Aminoglycosides, resistance, Escherichia coli, UTI.

\section{INTRODUCTION}

Urinary tract infections (UTIs) are among the most common types of bacterial infection acquired both from the community and nosocomial. There are two types of UTI: hospital associated urinary tract infection (HAUTIs), and community-associated urinary tract infection (CAUTIs).Women are the predominant group of the patients with CAUTIs [1]. UTIs were estimated to represent 100,000 hospitalizations, 7 million visits and 1 million admissions to emergencyservices in USA. The economic and public health loads of UTIs is radical and markedly affect the quality of life of infected patients [2].

The plurality of UTIs are caused by E. coli bacteria followed by proteus and other Enterobacteriaceae. However, among bacteria causing UTIs, E. Coli is considered as the most dominant cause of both community and hospital acquired UTIs. Because E. Coli accounts for up to $80 \%$ of community-acquired uncomplicated UTIs, these bacteria should be targeted when choosing experimental antibiotics [3].

Antibiotics commonly recommended for treatment of UTIs include co-trimoxazole, Nitrofurantoin, Ciprofloxacin and Ampicillin. How-ever there is worldwide increase in antibiotic resistance among urinary tract pathogens which limit treatment options. The Aminoglycosides are strong bactericidal agents that inhibit bacterial protein synthesis by joining to the $30 \mathrm{~S}$ ribosomal subunit. They are often used in combination with either a b-lactam or a glycopeptides, particularly in the treatment of E. coli UTI, as these drugs act synergically[4].

Copyright $\odot 2020$ The Author(s): This is an open-access article distributed under the terms of the Creative Commons Attribution 4.0 International License (CC BY-NC 4.0) which permits unrestricted use, distribution, and reproduction in any medium for noncommercial use provided the original author and source are credited. 
The application may be limited by occurrence of resistant strains in treatment. Various mechanisms are playing a role in the development of Aminoglycoside resistance but the existence of Aminoglycoside of modifying enzymes is the most clinical and epidemiological value. Antimicrobial resistance of urinary pathogens is increasing globally. Antibiotic resistance analysis showed among $276 \mathrm{E}$. coli isolated from clinical specimens, $39 \%$ of isolates were found to be resistant to most popular antibiotics [5].

Other study showed that out of $247 \mathrm{E}$. coli isolates about $82 \%$ of isolates were found to be resistant to numerous antibiotics [6].Therefore the current study is conducted to detect the percentage of resistant of E. coli strains that causes UTI to selected aminoglycosides.

\section{METHOD}

Specimen and sample processing

A total of 70 urine specimens were collected consecutively from in and out-patients at Shendi Teaching Hospital and AlmakNimer University Hospital, Shendi, Sudan. The collection was done by trained medical personnel avoiding contamination. Clean-catch mid-stream urine samples were collected from consenting patients. The specimens were immediately transported to the laboratory after collection and processed. All contaminated urine specimens and all patients refused to fill the consent form were excluded from the study [7].

\section{Isolation and identification}

A loop-full $(0.001 \mathrm{ml})$ of well mixed uncentrifuged urine was streaked onto the surface CLED agar. The plates were incubated aerobically at $370 \mathrm{C}$ for 18-24 hours and counts were expressed in colony forming units (CFU) per milliliter (mL). A count of 10[5] CFU/Ml or more was considered significant bacteruria. E.coli species were identified based on colonial morphology, indirect gram staining reaction, and biochemical tests [8].

\section{Antimicrobial susceptibility testing}

This was done using the Kirby Bauer Disc diffusion method with reference to the Clinical Laboratory Standard Institute (CLSI) performance guideline for antimicrobial susceptibility testing. Quality was assured by testing the E. coli quality control strain, ATCC 25922, in every batch. All zones of inhibition determined were within the ranges prescribed by the CLSI. Five aminogycosides were applied; Tobramycin 10mg, Kanamycin 30mg, Streptomycin 10 mg, Gentamicin $10 \mathrm{mg}$, and Amikacin 30mg [9].

\section{RESULTS}

This study was conducted in Shendi town, River Nile state to detect Aminoglycosides resistance among E. coli species isolated from patients with urinary tract infection. In this study a total of (70) participants were included the majority of them $(84.3 \%)$ were females and $(15.7 \%)$ were males (Table 1). Their age rangedfrom (4) to (67) years, more than $41 \%$ were within the age group (31-60 years) (Table 2). In this study E. coli was the most frequent isolated pathogen among UTI patients $(55.7 \%)$ (Table 3$)$.

The study revealed that the resistance of isolated E. coli species to Aminoglycosides was: $53.8 \%$ to Tobramycin, $48.7 \%$ to Kanamycin, $43.6 \%$ to Streptomycin, $28.2 \%$ to Gentamicin, and $12.8 \%$ to Amikacin,. The isolated species of $E$. coli showhighest resistance to Tobramycinand the lowest resistance level was detected against Amikacin. The study also revealed that the overall resistance of isolated $E$. coli species to aminoglycosides was $37.4 \%$ (Table 4).

Table-1: Shows distribution of study population according to gender

\begin{tabular}{|l|c|c|}
\hline Gender & Number & Percent (\%) \\
\hline Male & 11 & $15.7 \%$ \\
\hline Female & 59 & $84.3 \%$ \\
\hline Total & 70 & $100 \%$ \\
\hline
\end{tabular}

Table-2: Shows distribution of study population according to age

\begin{tabular}{|l|c|c|}
\hline Age group (years) & Number & Percent (\%) \\
\hline $1-30$ & 18 & $25.7 \%$ \\
\hline $31-60$ & 29 & $41.4 \%$ \\
\hline Above 60 & 23 & $32.9 \%$ \\
\hline
\end{tabular}


Table-3: Shows the Percentage of UTI caused by $E$. coli:

\begin{tabular}{|l|c|c|}
\hline Causative agent & Number & Percent (\%) \\
\hline E. Coli & 39 & $55.7 \%$ \\
\hline Others & 31 & $44.3 \%$ \\
\hline Total & 70 & $100 \%$ \\
\hline
\end{tabular}

Table-4: Shows the resistance of $E$. coli to selected Aminoglycosides

\begin{tabular}{|l|l|l|l|l|l|l|l|l|l|l|l|l|}
\hline \multirow{2}{*}{ Pattern } & \multicolumn{2}{|c|}{ Tobramycin } & \multicolumn{2}{|c|}{ Gentamicin } & \multicolumn{2}{|c|}{ Streptomycin } & \multicolumn{2}{|c|}{ Amikacin } & \multicolumn{2}{|c|}{ Kanamycin } & \multicolumn{2}{|c|}{ Total } \\
\cline { 2 - 13 } & No & $\mathbf{\%}$ & No & $\mathbf{\%}$ & No & $\mathbf{\%}$ & No & $\%$ & No & \% & No & \% \\
\hline Sensitive & 18 & $46.2 \%$ & 28 & $71.8 \%$ & 22 & $56.4 \%$ & 34 & $87.2 \%$ & 20 & $51.3 \%$ & 122 & $62.6 \%$ \\
\hline Resistant & 21 & $53.8 \%$ & 11 & $28.2 \%$ & 17 & $43.6 \%$ & 5 & $12.8 \%$ & 19 & $48.7 \%$ & 73 & $37.4 \%$ \\
\hline Total & 39 & 100 & 39 & 100 & 39 & 100 & 39 & 100 & 39 & 100 & 195 & 100 \\
\hline
\end{tabular}

\section{DISCUSSION} tract infection.

This study was conducted to detect Aminoglycosides resistance in E. coli isolated from patients with urinary

The study shows that the infection was highest in females with $84.3 \%$ as compared to 15.7 in men. This is in similar to previous studies conducted by Dason et al. which showed that the UTI was more commonly occurred in women than men [10].

The prevalence of bacterial UTI was highest in the age group 31-60 years (41.4\%); this finding was disagreed with results obtained by Martin Odoki et al. in Uganda, who reported that the prevalence was highest in 20-29 age groups. This difference may be due to that in our own study we collect mostof samples from pregnant UTI patients whomainly found in this age group [11].

In this study E. coli was the most predominant causative agent which was responsible of (55.7\%) of urinary tract infections, This finding is in agreement with result obtained by Devanand P. and Ramchandra S. who indicated the same result [12].

The study showed that the resistance of E. coli to Amikacin was (12.8\%), Gentamicin (28.2\%), Tobramycin $(53.8 \%)$, this result different from other result obtained by Helio et al. who reported that resistance of $E$. coli to the same antibiotic was $(0.4 \%),(6.5 \%),(6.5 \%)$ respectively[13].

Also the study denoted that the resistance of isolated E.coli species to streptomycin was (43.6\%), and to Kanamycin $(48.7 \%)$, and this disagreed with result of Sumera et al. who showed that the resistance of E. coli to streptomycin $(30 \%)$, and to Kanamycin (19.9\%). This difference of findings may be attributed to the difference in the period between the two studies, in which the less resistance level was detected in the studies conducted in time earlier than this current recent study, and this may be justified by distribution of the resistant strains of E. coli among patient either due to bad community practices or deficient in implementation of infection control guidelines in hospital and health care facilitates [14].

The study revealed that the resistance of E. coli to Aminoglycosides was (37.4\%), this finding is in difference with result obtained in America by Michael et al. who reported that the percentage of resistance in E. colispecies to Aminoglycosides was $(0 \%)$; this difference may be attributed to misuse of antibiotics which defined as the use of a substance for a purpose not consistent with legal or medical guidelines, and overuse which means taking a larger dose thanyou are supposed to. These bad habits in our country result in an increased risk of antibiotic resistance [15].

\section{CONCLUSION AND RECOMMENDATIONS}

The research established that the total resistance of isolated E. coli species to aminoglycosides between the participants was $37.4 \%$ the most influential Aminoglycoside against E. Coli was Amikacin. Further studies are recommended with large sample size.

\section{REFERENCES}

1. Car, J. (2006). Urinary tract infections in women: diagnosis and management in primary care. Bmj, 332(7533), 9497.

2. Kostakioti, M., Hultgren, S. J., \& Hadjifrangiskou, M. (2012). Molecular blueprint of uropathogenic Escherichia coli virulence provides clues toward the development of anti-virulence therapeutics. Virulence, 3(7), 592-593. 
3. Kang, C. I., Kim, J., Park, D. W., Kim, B. N., Ha, U., Lee, S. J., ... \& Wie, S. H. (2018). Clinical practice guidelines for the antibiotic treatment of community-acquired urinary tract infections. Infection \& chemotherapy, 50(1), 67100.

4. Schmitz, F. J., \& Jones, M. E. (1997). Antibiotics for treatment of infections caused by MRSA and elimination of MRSA carriage. What are the choices?. International journal of antimicrobial agents, 9(1), 1-19.

5. Soleimani, N., Aganj, M., Ali, L., Shokoohizadeh, L., \& Sakinc, T. (2014). Frequency distribution of genes encoding aminoglycoside modifying enzymes in uropathogenic E. coli isolated from Iranian hospital. BMC research notes, 7(1), 842 .

6. Ibacache-Quiroga, C., Oliveros, J. C., Couce, A., \& Blázquez, J. (2018). Parallel evolution of high-level aminoglycoside resistance in Escherichia coli under low and high mutation supply rates. Frontiers in microbiology, 9, 427.

7. Ouslander, J. G., Schapira, M., \& Schnelle, J. F. (1995). Urine specimen collection from incontinent female nursing home residents. Journal of the American Geriatrics Society, 43(3), 279-281.

8. Heuck, C. (1999). District Laboratory Practice in Tropical Countries. Bulletin of the World Health Organization, 77(1), 96-96.

9. Harding, G. K., Zhanel, G. G., Nicolle, L. E., \& Cheang, M. (2002). Antimicrobial treatment in diabetic women with asymptomatic bacteriuria. New England Journal of Medicine, 347(20), 1576-1583.

10. Dason, S., Dason, J. T., \& Kapoor, A. (2011). Guidelines for the diagnosis and management of recurrent urinary tract infection in women. Canadian Urological Association Journal, 5(5), 316.

11. Odoki, M., Almustapha Aliero, A., Tibyangye, J., Nyabayo Maniga, J., Wampande, E., Drago Kato, C., ... \& Bazira, J. (2019). Prevalence of bacterial urinary tract infections and associated factors among patients attending hospitals in Bushenyi district, Uganda. International journal of microbiology, 2019.

12. Prakash, D., \& Saxena, R. S. (2013). Distribution and antimicrobial susceptibility pattern of bacterial pathogens causing urinary tract infection in urban community of meerut city, India. International Scholarly Research Notices, 2013.

13. Sader, H. S., Jones, R. N., Winokur, P. L., Pfaller, M. A., Doern, G. V., Barrett, T., ... \& SENTRY Study Group. (1999). Antimicrobial susceptibility of bacteria causing urinary tract infections in Latin American hospitals: results from the SENTRY Antimicrobial Surveillance Program (1997). Clinical Microbiology and infection, 5(8), 478-487.

14. Sabir, S., Anjum, A. A., Ijaz, T., \& Ali, M. A. (2014). Isolation and antibiotic susceptibility of E. coli from urinary tract infections in a tertiary care hospital. Pakistan journal of medical sciences, 30(2), 389.

15. Goodlet, K. J., Benhalima, F. Z., \& Nailor, M. D. (2019). A systematic review of single-dose aminoglycoside therapy for urinary tract infection: is it time to resurrect an old strategy?. Antimicrobial agents and chemotherapy, 63(1). 